\title{
Searching for an Executive Head? Leadership and UNAIDS
}

\section{Sophie Harman}

Abstract: Leadership is one of the central explanatory factors for change within international organisations, yet is often sidelined as a part of wider social processes or understood in the context of domestic and managerial political agency. This paper adopt one of the few understandings of leadership within international organisation - Robert Cox’s 1969 essay on the Executive Head - as an analytical model for understanding leadership within global HIV / AIDS governance. It does so by applying Cox's framework of analysing the role of the executive head in relation to the international bureaucracy, member states, and the international system to the position of the ex-Executive Director of the Joint United Nations Programme on HIV/AIDS (UNAIDS), Peter Piot. The paper argues that the role of leadership transcends the agency of simply opening up the black box of international organisations, but is a realm of political knowledge and agenda-setting that is integral to the formation and subsequent longevity of international institutions, alliances, and the global issues that justify their existence.

Key words: Leadership, UNAIDS, Robert Cox, HIV/AIDS

Dr Sophie Harman

Senior Lecturer

Department of International Politics

School of Social Sciences

City University

London

EC1V 0HB

UK

Sophie.harman@,city.ac.uk

Tel. +44(0)207040 4511 


\section{Searching for an Executive Head? Leadership and UNAIDS}

Trends of institutional prominence and relevance within global health governance have often relied on the individual leadership of specific health organisations. New leadership can introduce vigour, direction, inertia and division between organisations. The Joint United Nations Programme on HIV/AIDS (UNAIDS) welcomes its new Executive Director, Michel Sidibe, at a time when leadership and direction has never been so important: the international community is concerned about a decline in funding and attention to the global HIV/AIDS epidemic, and the number of actors involved in the global response to the epidemic is at its confusing and contradictory height. Leadership is one of the central explanatory factors for change within international organisations, yet it is often sidelined as a part of wider social processes or under-theorised as a form of political agency. This paper argues that to understand the politics of global health, and specifically the politics of HIV/AIDS governance, one has to understand leadership. To do so it is vital to transcend descriptive analysis of institutional bickering and rivalry and adapt an analytical framework for the challenges of managing and sustaining an issue-specific international organisation. As such, this paper adopts one of the few understandings of leadership within international organisations - Robert Cox's essay on the Executive Head - and applies it to the role of Peter Piot as Executive Director of UNAIDS, 1995 - 2008.

The paper begins by reviewing how political leadership is conceptualised and how this conceptualisation pertains to understanding leadership within international organisation, before considering the context of leadership within the governance of HIV/AIDS. The paper then assesses the role of leadership within UNAIDS in regard to the international bureaucracy, the international system, and member states. Finally the paper draws together 
the main issues associated with leadership and UNAIDS and how they relate to global governance more broadly.

\section{Leadership, Cox, and 'the executive head'}

Writing in 1969, Cox's basic premise is that 'the quality of leadership may prove to be the most critical single determinant of the growth of in scope and authority of international organisation. ${ }^{11}$ While there have been allusions to this being the case in regard to executive heads such as Kofi Annan when Secretary General of the United Nations (1997 - 2006) or James Wolfensohn as President of the World Bank (1995 - 2005), there has been little direct engagement with leadership as a form of agency independent of a specific international organisation within the study of global governance. Leadership has long been one of the central concerns of processes and understandings of power, from Plato, to Weber's notion of legitimate authority and charismatic leadership ${ }^{2}$ to the presence of 'big man' or 'alpha male' leadership popular in psychological analysis. ${ }^{3}$ Leadership is often seen as somehow failing or inadequate, morally deficient and defined by charismatic individuals yet it is an integral feature of all organisations and economic and social development. ${ }^{4}$ Despite being a broad category of analysis, several themes can be discerned for understanding leadership.

The most common, is the role or pre-dominance of charisma or what Weber terms a 'personal gift of grace' derived from personal confidence and devotion on the part of the leader, passion, responsibility and a sense of proportion. Combined, these elements constitute a form of charismatic "hero' 5 that becomes a central method of categorising different types of leadership. ${ }^{6}$ A second theme is why followers obey, nominally out of either hope or fear and executive loyalty from the spoils of leadership. ${ }^{7}$ Nye's recent work on 
leadership suggests it is not fear but followers' need for meaning, cohesion, order and activity that infers authority to a leader. According to Nye, 'smart power' that builds upon leadership within and among followers is a central determinant of effective political leadership. 'Smart power' is the combination of hard and soft power that transcends the individual to recognise the power of dispersed leadership within communities and social movements by helping a group to achieve shared goals derived from either the group or the individual. $^{8}$

The final theme to be discerned from existing analysis on leadership is the importance of context and environment. It is this issue that perhaps pertains most crucially to understanding leadership within the context of international organisation. It is the environment or context in which leaders operate that give their actions political meaning and provide the arena in which to assess their quality ability to lead. ' The importance of environment for effective leadership requires a level of 'contextual intelligence, combining skill and emotional intelligence. ${ }^{10}$ This intelligence in the domestic sense is required to manage constitutional power, personal responsibilities, and events and circumstances. ${ }^{11}$ These arguments develop Cox's over-arching framework for understanding leadership in international organisation as resting on the following relationships: the international bureaucracy, member states, and the international system.

Based upon an ethical-normative approach to leadership, Cox utilises Haas' model of executive leadership as organizational ideology + committed bureaucracy + supporting coalition as the basis of analysis of three key relationships between the executive head and the world environment: the international bureaucracy; member states; and the 
international system. Haas perceives international organisation as a structure of 'institutionalized interest politics' that 'may well acquire the position of an autonomous actor at some future stage' within a world environment or system. ${ }^{12}$ Executive leadership is considered a 'politically adapted function' that is able to manipulate certain input pressures and various conflicts within this environment that in turn enables the organization 'to expand its tasks and enhance its authority' whilst maintaining a link with the evolution of the world system. ${ }^{13}$ This politically adapted function has taken on its own form in relation to the governance of HIV/AIDS, particularly in the case of UNAIDS and its first Executive Director, Peter Piot.

\section{UNAIDS and leadership squabbles in governing HIV/AIDS}

Since its inception in 1995 and official launch in 1996, leadership has been central to the relevance and potential longevity of UNAIDS. The principle role of UNAIDS is to coordinate UN efforts to combat HIV/AIDS at the global, regional and national level. It is to galvanise support and efforts for combating HIV/AIDS, provide strategic direction, support states with high HIV prevalence, and produce data on the status of the epidemic. The Executive Director of UNAIDS is responsible for the framing of the epidemic in such a way that gains global support, and crucially funding. UNAIDS must sustain a high level of strategic leadership with a clear vision that revitalises both the internal and external bureaucracy, and maintains the high level of funds directed to combat the disease.

The ability of UNAIDS as an institution to do so is mired by the fragile context of leadership in which it was established. The lead agency for the global response to HIV/AIDS was initially the World Health Organisation (WHO) through its Global 
Programme on AIDS (GPA), headed by Jonathan Mann. Mann was adept at articulating a rights-based approach to HIV/AIDS that established the foundations of the epidemic being seen as more than a health issue. However, this rights-based approach and the need to go beyond framing HIV/AIDS as a health issue ultimately led to the departure of Mann and the demise of GPA within the WHO. The appointment of Hiroshi Nakajima as DirectorGeneral of the WHO in 1988 saw the resurgence of a public health approach to the institution's operations, and crucially attempts to reign in the spending and autonomy of the GPA. ${ }^{14}$ Key to which was limiting the authority of Mann and the need to mainstream the GPA within the wider structures and programmes of the WHO. The combination of limiting GPA's budget, reducing the programme's autonomy, and bringing the GPA in line with the WHO's regional structures and public health led to the resignation of Mann in 1990. The resignation of Mann saw the beginnings of the WHO's institutional decline. Up until this point the GPA had been successful in setting the right-based agenda, highlighting non-health specific issues such as stigma and the need for education, raising the profile of HIV/AIDS across the world, and providing an information exchange and advice for countries confronting their epidemics. However the loss of Mann and the change in direction saw the dissolution of GPA, and the removal of HIV/AIDS out of the WHO into a stand alone, UN co-ordinating agency: UNAIDS. ${ }^{15}$ UNAIDS, thus assumed a leadership role from the ashes of the GPA in the context of two competing approaches to HIV/AIDS that mark problems with its governance today: the contention between the need to treat the disease as an exceptional, development issue, or the need to address HIV and AIDS as a biomedical issue. Leadership within global HIV/AIDS governance thus comes to constitute a balancing act of competing demands under the banner of co-ordination, but also a need for direction in the absence of any over-arching authority. 
The role of leadership within UNAIDS is important for the following reasons. First, it is the lead agency appointed by the UN to manage and co-ordinate the HIV/AIDS response. It has to provide co-ordination and direction for a significant number of donors, governments, civil society actors, and international bureaucrats through centralised and decentralised offices across the world. Second, it does not have the financial power to influence states as other actors within HIV/AIDS governance, such as the World Bank or the Global Fund to fight AIDS, Tuberculosis and Malaria (the Global Fund) may have. It thus has to exert a form of consensual soft power. Third, for many Peter Piot, was not only UNAIDS, but was the global response to the epidemic. It is thus integral to assess not only how he came to occupy this position in peoples minds, but the lessons of his leadership and their implications for the future of UNAIDS. In considering the international bureaucracy, the international system and member states in turn, this paper will consider how UNAIDS established clear policies and frameworks in which the current global HIV/AIDS response currently operates and the role of Piot's leadership within this.

\section{International Bureaucracy}

The executive head's relationship with top officials within the international bureaucracy is crucial to understanding leadership in international organisation. The role of top officials can often lead to conflicting poles of authority and divisions of loyalty that despite being present in most large organisations, when senior staff members garner external - i.e. member state support for their position. The legal-institutional procedures within, combined with the collegial nature of, the international bureaucracy result in the executive head having limited authority over top official appointments and the sector of the bureaucracy's work that is 
allocated to them, giving some senior officials a large amount of influence and relative autonomy. Cox identifies three central ways of maintaining leadership among such conditions. First is the complete domination and centralization of power through making frequent changes in responsibility. Second, the executive head should preside over officials and promote communication and collective discussion whilst making 'major decisions on policy after consultation rather than in consultation with his top officials.' Third, the executive head should maintain a 'reserved area of policy' and construct effective personal staff coalitions. Matters that are not of direct concern should be delegated. ${ }^{16}$

During his leadership, Piot was effective at both maintaining a centralised form of power, and loyalty among a select group of top officials. In line with Cox's recommendations, Piot was able to do so through a combination of building a specific epistemic community that had its roots in the defunct GPA, and occupied a centralised form of leadership through his ability to set a clear agenda and priority areas for the institution. Upon his appointment, Piot identified in his own mind the need to give voice to people living with HIV 'regardless of what states and co-sponsors and all the globe say, frankly, I couldn't care less. ${ }^{17}$ This voice and direction would be based upon scientific evidence where it exists, and specific values based upon human rights, and forms of equality such as gender equality. To put his agenda into practice, he adopted a medium term view and a short term view of what could be achieved and what to push for and when, ${ }^{18}$ and a reserved area of policy-making 'that increasingly relied on informal brainstorming sessions involving knowledgeable and influential 'outsiders". ${ }^{19}$ Hence, key to Piot's leadership was the formation of a specific epistemic community, that resembled more of a broad alliance made up of colleagues from the GPA, as well as scientists and actors from civil society that were not necessarily from the 
UN system. These actors form the current 'gatekeepers' of the global response to HIV/AIDS, and have come to occupy senior positions with the World Bank, the Global Fund, and the UN. Individuals such as Richard Feechem - ex Executive Director of the Global Fund, Jonathan Mann - former head of the GPA, and Debrework Zewdie - exDirector of the Global HIV/AIDS Program, World Bank and the current Deputy Executive Director of the Global Fund, have been crucial in shaping how states, intergovernmental organisations and civil society react to HIV/AIDS, and establishing the rights-based agenda for the disease alongside Piot. As Piot describes it 'when AIDS started I was very young, I was about 30 something and so we were the young turks... no opportunism but we were passionate about it... but now they are still there, the same characters. ${ }^{20}$ Leadership within the international bureaucracy cannot be solely attributed to Piot, but is shared among key individuals that have developed a prominent role for themselves and the institutions they represent. In coming together to form a coherent 'one voice' alliance, such senior figures are able to reinforce each others leadership and authority within their respective organisation. The success of establishing UNAIDS as the central co-ordinator of the global HIV/AIDS response, stems from the formation of alliances beyond a narrow epistemic community of experts to include civil society, the state and the private sector. It is such alliances that are fundamental to the effective management of member states and the maintenance of older, UN-based agencies at the forefront of leadership within the wider international system, as the paper discusses in more detail below. The buildings of alliances both within and outside of the institution were crucial components of Piot's leadership of UNAIDS, as he describes the process 
it is also about capitalising on alliances that have been made in the past. In the beginning it was very slow in building up but after a while you know who you can count on and who not, the ones who stab you in the back and the ones who have all the problems. But these alliances may change also, but I think that it is true for the UN system overall. ${ }^{21}$

Important to the formation of such alliances was the need to establish legitimacy for leadership. This can be achieved through personality, and past working friendships, however a key factor for Piot's legitimacy was his ability to carve out a specific functional expertise, using his agency as a microbiologist at the forefront of HIV/AIDS research: specifically in sub-Saharan Africa, where at the time of his appointment the impact of the disease was starting to unravel. Not only did Piot have the scientific credentials to develop legitimacy for his leadership role, he had a prominent position in identifying the 'third epidemic' of HIV/AIDS, that of the social, political and cultural reaction to the epidemic. As early as 1988, Piot in partnership with Jonathan Mann had begun to frame HIV/AIDS more than just a health issue, but a rights-based, exceptional, development issue. ${ }^{22}$ Thus, not only did Piot use his scientific expertise to project a degree of legitimacy, he used it to extend the remit of debate associated with HIV/AIDS, and as a consequence expanded the mandate and relevance of UNAIDS. Piot framed UNAIDS as a non-health specific agency that had the credentials of scientific research and data collection combined with the necessary rhetoric and expertise of a development oriented institution.

For Cox, agenda-setting and maintenance of a close-knit group of advisors must be balanced with the desire not to alienate important parts of the institution in regard to internal resistance to change and external influence that may lead to potential confrontation. The 
only way for the executive head to overcome such inertia is to introduce new staff as a means of innovating new ideas. ${ }^{23}$ For Piot, this was relatively straightforward, as being the first Executive Director of UNAIDS he had a certain degree of autonomy to establish the foundations of the institution with a staff that he had developed. A principle means of overcoming inertia for Piot was to continue to broaden UNAIDS' mandate and decentralise the institution's operations to give regions and countries a degree of autonomy within the overarching framework set by the senior leadership in Geneva. Both regional and country teams have the room to articulate specific interests and develop joint advocacy programmes within the organisation ${ }^{24}$ within the guidelines set out by the Global Task Team on Improving AIDS co-ordination, established by UNAIDS' secretariat and the United Nations Development Group. ${ }^{25}$ These guidelines extend to not only the UNAIDS bureaucracy, but all UN agencies working in-country on HIV/AIDS. They stress the need for greater clarity as to role and responsibilities, simplification and harmonization of UN support to the national response, and an over-arching commitment to the role of UNAIDS as the main coordinator of the global response. ${ }^{26}$

The evolution of UNAIDS from the GPA suggests the role of the international bureaucracy is vital to successful leadership as it is the basis for institutional support, direction, and organisational funding. The case of Piot suggests effectiveness within the international bureaucracy requires a combination of the type of skill and emotional intelligence Cox outlines, with legitimacy. Such legitimacy is drawn from personal background and expertise, but also the reinforcement of a wider epistemic community of both HIV/AIDS experts and health workers and senior figures within international institutions. A good grounding within the international bureaucracy both opens up and maintains the space in which UNAIDS is 
able to operate in governing global health. The international bureaucracy provides the foundation for alliance formation that transcends narrow epistemic communities in specific institutions to encompass wider participation from the international system and member states. A lack of legitimacy and broad bureaucratic support will undermine any attempts at institutional change or relevance within the broad spectrum of the international system.

\section{Member States}

The second key relationship that Cox identifies as central to effective leadership is that between the executive head and member states. Cox identifies the relationship with member states as being the determinant of capability for action, initiative and political support. Such a relationship is fraught with difficulty as issues that are important to executive heads are rarely important to national governments who are more responsive to local political influences and international issues or problems that are seen as a threat to their national security. The interests of international organisations have to be aligned with the domestic interests of states, thus the executive head has to have an acute understanding of both global and domestic politics. The Executive Director of UNAIDS must form alliances with key donor states such as the US, states with high levels of HIV prevalence rates, specifically in subSaharan Africa, and states with the threat of large epidemics such as Russia and China. To do so, according to Cox, the executive head requires i) political skill; ii) a personal confidential intelligence network involved in the domestic politics of key countries; and iii) the ability to compromise and to reconcile such compromise with ideological clarity and authority. ${ }^{27}$

Member state interests as to how to effectively combat the disease, and the level of political commitment required to do so differ substantially. Getting government recognition and 
public acknowledgement of a country's HIV/AIDS epidemic is paramount to the work of UNAIDS. The Executive Director must manage two kinds of state relationship: i) that with countries with high HIV prevalence, often reliant on foreign aid to finance their health interventions; and ii) those member states that are large international donors. In regards to the first category, the executive head must first encourage state leaders to recognise their epidemic if necessary, before suggesting measures and means of addressing it. This has been problematic with particular states in sub-Saharan Africa that have either been in denial about the relationship between HIV and AIDS or denial as to the extent of the problem and its political ramifications. Of those states that have acknowledged the problem and are taking measures to treat and prevent HIV, UNAIDS has to represent and protect their ability to do so, and the knowledge and experience they offer to global policy-making. In this sense, UNAIDS must help such states elicit financial and political support for their HIV/AIDS interventions, whilst representing their interests and maintaining the policy space for them to direct and design their own programmes. The executive head must present themselves as an ally to such states or else threaten their sense of legitimacy, trust and autonomy from more powerful lender states.

Whereas the relationship with the first kind of member state involves trust and the need to elicit political will, the second relationship involves both the need for political will, the resulting funds such will presents, and to manage the expectations and objectives of donor money. The US is perhaps the most difficult of member states the executive head engages with. George W. Bush's President's Emergency Plan for AIDS Relief (PEPFAR) has been very contentious within the HIV/AIDS community for its stress on abstinence-based prevention policies, and the restrictions it placed on funds towards family planning and 
reproductive health organisations. PEPFAR is, however, the largest bilateral commitment to combating the disease, and hence, the influence it has over the epidemic's governance at the global and national level is substantial. Whilst some of the more contentious aspects of PEPFAR have been addressed, the administration of Barack Obama has generated further controversy within the HIV/AIDS community in regards to potential cuts in funding. Having initially pledged an extra US $\$ 50$ billion of US money to combat HIV/AIDS by 2013, in practice Obama has only increased spending on HIV/AIDS by $2.5 \%$ as part of a wider strategy on global health. These two examples reflect the continuous problem for leaders of intergovernmental organisations: how to bridge the divide between words and deeds, and how to offer an opinion and provide leadership in reaction to contentious subjects whilst maintaining broad member state support.

Beyond PEPFAR and bilateral global health initiatives, the US is home to large philanthropic foundations such as The Bill and Melinda Gates Foundation and the William J. Clinton Foundation, the centre for biomedical research into methods of prevention and cure of HIV such as the Harvard AIDS Initiative, the American Foundation for AIDS Research (amFAR), and the National Institutes of Health, as well as new forms of anti-retroviral treatment developed by large pharmaceutical companies. The US government thus has multiple domestic interests in regard to company profit, the protection of property rights, and the promotion of the US as an altruistic global force for good. The Executive Director must find a balance between maintaining a working relationship with the US, whilst reflecting the interests and needs of the wider HIV/AIDS community of which the US is not exempt. Whilst the US is perhaps an extreme example, the executive head must manage these issues of balancing donor and borrower interests with a range of current donors- such 
as the G8 countries - as well as courting potential new donors such as China and the United Arab Emirates.

Piot would suggest that in practice such a balancing act requires a combination of alliance and coalition-building with states, intelligence networks and international organisations incountry, and the use of the media and non-state actors in holding such states to account. As Piot describes it

You have your friends, you have your enemies and you have the ones in-between. So you have to take care of your friends, you have to make sure your enemies don't eat you and then the ones in-between you bring on your side and isolate your enemies ${ }^{28}$

During his leadership, Piot used a variety of mechanisms to compromise and push member states in the pursuit of UNAIDS over-arching agenda through what he describes as a form of 'convening power. ${ }^{29}$ The first of which was alliance-building with the friends and enemies he described, and to develop institutional partnerships at the in-country level. This is specifically the case with the development of the National AIDS Council system of governance within countries. As co-ordinators of in-country responses, these government agencies are seen by UNAIDS as their country-counterparts, as ex-Country Co-ordinator for UNAIDS, Kenya, describes 'when we are talking about our national counterpart we mean the national AIDS council, of course. ${ }^{30}$ These councils help articulate and plan around the same directives and initiatives within UNAIDS, and are a key mechanism of member state alignment to the wider objectives of the institution. By building alliances with these councils, the leadership of UNAIDS is able to develop political will and enact specific policies from 
within the state. Similar to Haas' understanding, developing policies alongside such councils, enables UNAIDS to integrate states with high HIV prevalence into the wider process of global decision-making and align policies to fit the institution's over-arching objectives. This is done in a manner that promotes the collaborative 'support' role of UNAIDS put forward by in-country Directors and the Executive Director. The presentation of UNAIDS as an 'honest broker' or intermediary between different states, more specifically, between borrower and donor states, makes the institution relevant to any form of co-ordination within the global response and thus confers legitimacy on the institution as an intermediary. The building of alliances with donor countries can be more complex at the global level, but similar to borrower states, predominantly occur at the in-country level. By decentralising authority and decision-making in implementation to Country Directors, the Executive Head builds power and legitimacy from the bottom-up.

The second mechanism of managing member states is to exploit or manipulate their position or perceived position within the wider international system. Piot recognised the need for countries to gain the right kind of position within the international community and not to be outcast from the global HIV/AIDS agenda. Aware of this position, Piot's role was two-fold; he had to raise the issue of HIV/AIDS to such a global public level that it could be used as a shaming device for member states where necessary, and then hold states to account for it. The Executive Director must be consistent and follow the same objectives and ideology among all states. When dealing with individual states, the head must establish what the boundaries are in regard to a particular issue and then push where necessary. For example, Piot addressed US interests in regard to the PEPFAR era, by both praising Bush's state of union address in 2001, in which PEPFAR was announced, for setting a trend and changing 
'the international perspective on AIDS funding in the western world', as well as condemning wider aspects of the project, such as the suspension of funds to the United Nations Population Fund (UNFPA) on account of their work with family planning. ${ }^{31}$ Similarly, the executive head must identify an issue or initiative and stick with it despite various contentions between different states. For example, during his leadership, Piot put the need for an international consensus on what constitutes HIV prevention, despite contention with many different states over injecting drug users, abstinence, and homosexuality. For him, it was crucial to organise around one issue and then push for it. This organisational concept has been applied in practice through 'The Three Ones' co-ordinating mechanism. 'The Three Ones' relate to the need for one co-ordinating body, one strategic plan, and one monitoring and evaluation system in-country. ${ }^{32}$ In taking responsibility for the deployment of such a framework, the executive head re-asserts the leadership in co-ordination role of UNAIDS, and in so doing, their position within the organisation and the wider international system. Moreover, they align member states within a clear framework of governance underpinned by their own specific ideology for the institution. Those organisations that do not conform to 'The Three Ones' are subject to shaming mechanisms, have to operate on the sidelines of the global response, and thus are less adept at receiving international financial support or credibility. The central relationship for such shaming mechanisms to work and the building of a global strategy is that of the international system.

\section{The International System}

The international system is the final relationship relevant to the consideration of leadership in international organisation. The executive head's perception of the international system and state actions and initiatives within it determines their role as either a prominent actor 
with personal agency or as a 'negotiator in 'quiet diplomacy'.33 For UNAIDS the relationship with the international system pertains to its engagement with its co-sponsors, non co-sponsors, and civil society organisations (CSOs). The magnitude of organisations involved with the delivery and agenda-setting of global HIV/AIDS concerns narrows and confuses the space for decision-making and the emergence of new ideas. The multiplicity of actors and initiatives has led to problems with co-ordination and direction within the response. These organisations exist in an arena marked by competition for funds, the need to demonstrate relevance and direction by asserting leadership as the lead agency within HIV/AIDS. To be effective the executive head has to ensure confidence of opinion, be identified with a definite ideology, have the acumen to be constructive, and have supplementary intelligence from outside the organisation. ${ }^{34}$ Most importantly, the executive head needs to build majorities in support of their policies and ideology whilst remaining independent of any form of coalition. One of the most basic qualifications for effective leadership thus is one of the oldest - mediation in negotiation.

As an agency within the UN, with the specific mandate of co-ordination, the most important relationship for the Executive Director of UNAIDS is with the institution's co-sponsors: the World Bank, the WHO, the ILO, UNICEF, UNFPA, UNDP, UNHCR, WFP, and UNESCO. UNAIDS has the role of co-ordinating the technical support of each of the cosponsors through the identification of 'lead organisations' and 'main partners' on specific issues, 'The Three Ones' at the in-country level and the Committee of Cosponsoring Organisations (CCO). The CCO functions as the main steering committee of UNAIDS: it reviews the budget, financial proposals and reports; it makes approval recommendations on aspects of the organisation and reports to the Programme Coordinating Board (PCB) as to 
the mainstreaming of strategy and the activities of the co-sponsors. ${ }^{35}$ The CCO can be seen as a tool of the Executive Director in that it performs the necessary checks and balances for the institution and against each of the co-sponsors.

Co-ordinating mechanisms by their very nature limit the scope of UNAIDS and the leadership of Piot. Within global health governance there is a drive towards the new and innovation, and the need to provide co-ordination for a range of activities and actors. Leadership within a co-ordinating agency such as UNAIDS must find the balance between co-ordination and mediation, and providing direction and autonomy separate from its cosponsors and member states. Leadership performs a key function in this for issue-based institutions such as UNAIDS to transcend the co-ordination trap, effective leadership must establish a clear mandate and institutional approach. In framing the HIV/AIDS response as both a biomedical and development issue, Piot effectively pushed the mandate of UNAIDS as a means of gaining greater relevance within the international system. The extension of UNAIDS mandate, and the role of Piot within this is clear when mapping UNAIDS' flagship publication the AIDS Epidemic Update or 'the global reports' co-published with WHO. The earlier updates were mainly about data and information as to the status of the global epidemic, whereas come 2004, the updates included a preface from Piot noting the complexities of the epidemic and its response ${ }^{36}$ The 2004 report was the first all-out acknowledgement of UNAIDS' extension to issues of feminization of the epidemic, its linkages with security - a crucial position for garnering wider state support, and the need to go beyond basic engagement with state actors, in other words, it made a clear distinction from the biomedical-approach favoured by the WHO. ${ }^{37}$ 
The main threat to the ability of the executive director of UNAIDS to set and sustain a clear agenda for HIV/AIDS is the role of non-co-sponsors. Non-co-sponsors are other UN agencies such as UNIFEM, UN-aligned funding bodies such as the Global Fund to Fight HIV/AIDS, TB and Malaria, and philanthropic foundations such as The Bill and Melinda Gates Foundation. The increase in funds towards HIV/AIDS over the last ten years has seen a growth in the number of actors involved in its governance. Two central actors within this change in funding have been the Global Fund and The Bill and Melinda Gates Foundation. Established as part of the 2001 United Nations General Assembly Special Session on HIV/AIDS (UNGASS) declaration, the Global Fund is very much a part of the UN system, and is firmly identified as a funding body only. Piot showed successful leadership in maintaining a clear articulation of the division of responsibilities between the Fund and UNAIDS since its inception and subsequent growth. The founding Executive Director of the Global Fund, Richard Feachem (2002-2007) was very much one of the gatekeepers of HIV/AIDS governance alongside a close knowledge network of experts with Piot, having been the Director of Health, Nutrition and Population at the World Bank (1995 - 1999). The linkages between Feachem and Piot as part of a wider alliance organised around HIV/AIDS research in the early years of the disease generated ideological symmetry between the two executive heads whilst maintaining clearly delineated roles and responsibilities.

Perhaps the most direct confrontation to the role of UNAIDS within the international system is the Bill and Melinda Gates Foundation. As a private foundation run by the Gates family, the foundation does not, and does not have to be accountable to any actors. The Gates' approach is very much to offer financial support underpinned by evidence-based 
practice to states and non-state actors. Increasingly, actors have to fit in with the existing guidelines and approach, and research agenda of the Foundation. ${ }^{38}$ Hence, the Foundation has the financial weight and subsequent influence within the international system to operate outside of UNAIDS and 'The Three Ones'. To effectively address such an issue, the executive head must both encourage participation and partnership with the Foundation, whilst at the same time form allegiances with multiple actors as a buffer to the influence of the Foundation. Similar to engagement with member states, the executive head must deploy media and shaming tactics towards issues of accountability, inclusion and participation within the Foundation, as well as using existing relations with individuals in other agencies and co-sponsors to continue to promote UNAIDS' ideology. Legitimate leadership is crucial within this: UNAIDS has the legitimacy of the UN, member states and specific NGOs, and leadership credential of the executive director built upon personal background, state and non-state alliances, and perceived intermediary states. Legitimacy is something new actors such as the Bill and Melinda Gates Foundation lack and is thus central to UNAIDS maintaining institutional space for its own existence and the interests of all its member states. The executive head must use such legitimacy at selected points to manage such relationships balanced with a wider awareness of the agency of such Foundations and the need to bring them on side with UNAIDS wider mechanisms and objectives.

The third relationship the executive head must form within the international system is that of civil society. Civil society is integral to the autonomy of UNAIDS from member states and co-sponsors, as well as the mechanisms used by the Executive Director to manage such relationships and hold them to account. UNAIDS has a broad definition of civil society to include all non-state actors: commercial and non for profit organisations, and academic 
institutions. Engagement with civil society at both the national and the global level involves liaison committees, information sharing, joint advocacy, and the sharing of best practice and planning ideas. At least one of UNAIDS' Special Envoys tends to be drawn from civil society, and are thus representative within the executive leadership of the organisation. For example, Elizabeth Mataka, Special Envoy for AIDS in Africa, is the Executive Director of the Zambia National AIDS Network (ZNAN), and her predecessor, Stephen Lewis, is a prominent advocate and campaigner for improving the human condition and the rights of people living with HIV/AIDS and women. Beyond such formal structures, Piot encouraged representatives of civil society to contact him wherever possible, endeavouring to reply to emails, as well as ensuring a visit to civil society projects or meetings whenever in-country, specifically with people living with HIV. ${ }^{39}$ Mechanisms of engagement at the national level tends to be more inclusive of local civil society actors, whereas at the global level it is still dominated by organisations from the US as they 'are much better organised. ${ }^{40}$ Engagement with civil society by the executive head is an effective device to maintain their position at the forefront of new ideas and challenges emerging from the field. It extends their wider knowledge network, promotes alliance formation and assists in the trial of new ideas. Civil society and the media are effective tools for 'going loud' on contentious issues and shaming states into action. The backing and support of civil society infers wider legitimacy on the part of the executive head as they can have claims to interaction and relations with on-the-ground interventions and the wider HIV/AIDS community. It is this legitimacy and authenticity that is necessary for the exertion of soft power with the institution's relationship with other actors in the international system, as well as member states and the international bureaucracy. 


\section{UNAIDS and Leadership}

The relationship between the executive director of UNAIDS and the international bureaucracy, member states and the international system reveals several issues facing international institutions and the role of leadership specifically. UNAIDS operates within a global system marked by large public and private financing, member state difference and denial, and an ensuing narrowing of political space in which to operate. Compliance with global health targets and funding pledges has long been a problem between state-based actors and intergovernmental organisations, but the presences of actors such as the Bill and Melinda Gates Foundation with a budget triple that of the WHO makes co-ordination, joint commitments and adherence to global objectives difficult. As well as maintaining their own relevance to global issues, agencies such as UNAIDS must also help maintain the sovereignty of borrower state decision-making alongside the rights of their populations. UNAIDS represents a specific type of specialised agency which tends to be issue-based, with a co-ordinating mandate only and limited funding capacity or budget. These institutions come under the broad umbrella of the UN system which infers legitimacy but also limits their dynamism. Leadership is crucial to the relevance and longevity of such institutions. The executive head is the central point of legitimacy for a new institution and how it is arranged: it is their role to build support within the international bureaucracy, trust between and with member states, and alliances in the international system. This is important in the formation of the institution in shaping its ideology and approach to global issues, as well as providing the grounding for future institutional change and relevance in an ever-changing policy domain. Leadership that draws upon a broad alliance, personal knowledge and expertise creates legitimacy. Such legitimacy gives the executive head authority to set global agendas , 
take risks, and provide a leadership role not only within a specific institution but the global alliance in which in operates.

Alliances are essential to the balancing act institutions such as UNAIDS perform as a check on member state, non-state and bureaucratic power. Alliances outside the boundaries of individual institutions are paramount to their future development and sustenance, as well as ensuring the primacy of a specific issue of concern within the international community. The expertise of such alliances will help secure member state support and build trust, as well as offer guidance within the media as to what the issues are and how best to address them. To be successful alliances have to expand beyond the expert epistemic community to include a range of skills and opinion from the non-governmental and state sector. Alliances have drawn on resources from the media, civil society, states and institutions to maintain the high profile of HIV/AIDS as an exceptional issue, and thus the role of UNAIDS in being the expert co-ordinating agency in responding to this disease. In comparison, the GPA drew on a narrow epistemic community and failed to broaden the alliance to be inclusive of wider parts of the international system. Likewise, other global health issues such as malaria and tuberculosis have received less global attention than HIV/AIDS. These issues do have global alliances championing them in global policy-making; however what these alliances lack is a clear lead institution, and more importantly, a clear leader.

The role of Piot shows that to maintain institutional relevance and legitimacy, leaders must balance 'quiet' or 'soft' diplomacy with 'going loud' and establishing a presence as a lead authority figure on the issue they represent. Combined with the shift of leadership from a specific institution to a wider alliance, this leads to a fundamental problem with institutional 
leadership: whether leadership goes beyond the notion of path-dependent cumulative decision-making and the expression of a general position, to have an agency within international politics independent of an organisation. This poses a particular problem for UNAIDS with the departure of Piot. This problem reflects the domestic analogy between leaders of international institutions and state leaders: the predominance of the charismatic (male) leader, whom without the party, institution or country suffers. This is a narrow way of thinking about leadership in international institutions. As this article has argued, leadership is an integral component to the establishment and longevity of issue-specific co-ordinating agencies such as UNAIDS, but at the core of successful leadership is the removal of leadership from the institution into a broad alliance of states, institutions and non-state actors. Leadership should transcend the institution to develop a mutually reinforcing, legitimate, relationship between the institution and the alliance. Leadership has a specific agency within this relationship, but rests on skill, expertise, and legitimacy; less on notions of 'masculine' charisma. The future of UNAIDS will depend on the current executive director, Michel Sidibe's ability to build on the work of Piot and maintain such alliances and relevance of the institution in a changing playing field of HIV/AIDS funding, political will and global complacency towards the disease.

\section{Conclusion}

The role of leadership transcends the agency of simply opening up the black box of international organisations, it is a realm of political knowledge and agenda-setting that is integral to the formation and subsequent longevity of international institutions, and the alliances built around the global issues that justify their existence. The application of Cox's framework to Peter Piot reveals several issues pertinent to the governance of HIV/AIDS 
and global governance more broadly. Alliances drawn from epistemic communities are integral to the maintenance of legitimate leadership and institutional relevance in a competitive global policy area that is often dictated by those with the largest budget. Successful leaders must be at the centre of such alliances, and be pivotal in the establishment of their antecedents. The transcendence of executive power beyond institutions to the broad arena of global alliances suggests that leadership is a dispersed and non-institutional arena of authority. This notion requires further research, but it does indicate the importance of issuespecific co-ordinating agencies such as UNAIDS to the study of global governance, specifically the mechanisms and strategies they develop to maintain relevance in a narrow space. Whilst the role and position of UNAIDS as the lead agency for HIV/AIDS coordination is often under threat from competing interests and budget cuts, maintenance of alliances with the support of both a strong bureaucracy and member state trust will ensure its continued relevance. At the centre of managing these competing issues is the leadership of its Executive Director.

\footnotetext{
${ }^{1}$ Cox, R. (1969). 'The Executive Head: an essay on leadership in International Organisation,' in R. Cox with T. Sinclair Approaches to World Order (1996) Cambridge: Cambridge University Press, p317

${ }^{2}$ Weber, M. 1991. 'Politics as Vocation' in H.H. Gerth and C. Wright Mills (eds) From Max Weber: essays in sociology London: Routledge

${ }^{3}$ Ludwig, A..M. 2002. King on the Mountain: the nature of political leadership Kentucky: University of Kentucky
} 
${ }^{4}$ See Kellerman, B. 1999. Reinventing leadership: making the connection between politics and business New York: SUNY Press; Wren, J.T. 2007. Inventing Leadership Cheltenham: Edward Elgar Publishing; Blondel, J. 1987. Political leadership: towards a general analysis London: SAGE; Rondinelli, D.A., and Heffron, J.M. 2009. 'Leadership for development: an introduction' in D.A. Rondinelli and J.M. Heffron (eds) Leadership for development: what globalization demands of leaders fighting for change Sterling, VA: Kumarian Press p1-29 ${ }^{5}$ Weber, 1991

${ }^{6}$ For example, Burns' typology of transforming and transaction style leadership transforming referring to a leader articulating and implementing a specific vision for society, and transaction indicating that leaders engage in exchange and trade-offs as a means of maintaining stability and enacting change - is organised around the notion of heroes or villains, or 'the office-holder' or managers, ${ }^{6}$ i.e. with charisma or lacking in charisma.

${ }^{7}$ Weber, 1991

${ }^{8}$ Nye, 2008

${ }^{9}$ Blondel, 1987; Tucker, R.C. 1995. Politics as leadership London: University of Missouri Press; Zaleznik, A. 2008. Hedgehogs and Foxes: character, leadership, and command in organizations Hampshire: Palgrave MacMillan

${ }^{10}$ Nye, 2008

${ }^{11}$ Elcock, H. 2001. Political Leadership Cheltenham: Edward Elgar Publishing

${ }^{12}$ Haas, E. (1964) Beyond the Nation State: Functionalism and International Organisation Stanford: Stanford University Press

${ }^{13}$ Cox, 1969; Haas, 1964 
${ }^{14}$ Lisk, F. (2009) Global institutions and the AIDS epidemic: responding to an international crisis London: Routledge

${ }^{15}$ Lisk, 2009

${ }^{16}$ Cox, 1969

${ }^{17}$ Interview Piot, Peter. $6^{\text {th }}$ July 2009, London, UK

${ }^{18}$ Interview Piot, Peter. $6^{\text {th }}$ July 2009, London, UK

${ }^{19}$ Lisk, 2009

${ }^{20}$ Interview Piot, Peter. $6^{\text {th }}$ July 2009, London, UK

${ }^{21}$ Interview Piot, Peter. $6^{\text {th }}$ July 2009, London, UK

${ }^{22}$ Piot, P. and Mann, J. (1988) AIDS and HIV Infection in the tropics London: Balliere Tindall

${ }^{23}$ Cox, 1969

${ }^{24}$ Interview Schoultz, Kristan. 5th April 2005. UNAIDS - Kenya

${ }^{25}$ Interview Tembo, George. 25th May 2006. UNAIDS - Geneva, Switzerland

${ }^{26}$ United National Development Group. (2006) Proposed Working Mechanisms for Joint

UN Teams on AIDS at Country Level Guidance Paper $19^{\text {th }}$ May 2006

${ }^{27}$ Cox, 1969

${ }^{28}$ Interview Piot, Peter. $6^{\text {th }}$ July 2009, London, UK

${ }^{29}$ Interview Piot, Peter. $6^{\text {th }}$ July 2009, London, UK

${ }^{30}$ Interview Trama, Annalise. 21st December 2005. UNAIDS - Kenya

${ }^{31}$ Piot, P. in Goldman, B. et al. (2004) 'A prescription for change: using policy to win the battle against AIDS' Journal of World Affairs XI(1)

${ }^{32}$ UNAIDS. (2005) The 'Three Ones' in action: where we are and where we go from here Geneva: UNAIDS

${ }^{33}$ Cox, 1969 
${ }^{34}$ Cox, 1969

${ }^{35}$ UNAIDS. (2009) 'Committee of cosponsoring organizations (CCO)'

http://www.unaids.org/en/Cosponsors/CCO/default.asp (accessed September 2009)

${ }^{36}$ Piot in UNAIDS/WHO. (2004) Report on the Global AIDS Epidemic 2004 Geneva:

UNAIDS/WHO

${ }^{37}$ UNAIDS, 2004

${ }^{38}$ Global Health Watch. (2008) Global Health Watch 2 London: Zed Books; McCoy, D., Kembhavi, G., Patel, J., and Luintel, A. (2009). ‘The Bill and Melinda Gates Foundation's grant-making programme for global health' The Lancet 373: 1645-1653; McNeil, D.G. (2008) 'Gates Foundation's Influence Criticized' The New York Times http://www.nytimes.com/2008/02/16/science/16malaria.html (accessed July 2009)

${ }^{39}$ Interview Piot, Peter. $6^{\text {th }}$ July 2009, London, UK

${ }^{40}$ Interview Piot, Peter. $6^{\text {th }}$ July 2009, London, UK 